\title{
Editorial \\ Vitamin D or hormone D deficiency in autoimmune rheumatic diseases, including undifferentiated connective tissue disease
} Maurizio Cutolo

Research Laboratory and Acadenic Clinical Unit of Rheumatology department of Internal Medicine, University of Genova, Viale Bnedetto XV, 616132 Genova, Italy

Corresponding author: Maurizio Cutolo, mcutolo@unige.it

Published: 2 December 2008

This article is online at http://arthritis-research.com/content/10/6/123

Arthritis Research \& Therapy 2008, 10:123 (doi:10.1186/ar2552)

(c) 2008 BioMed Central Ltd

See related research article by Zold et al., http://arthritis-research.com/content/10/5/R123

\begin{abstract}
Epidemiological evidence indicates a significant association between vitamin $\mathrm{D}$ deficiency and an increased incidence of autoimmune diseases. The presence of vitamin $D$ receptors in the cells of the immune system and the fact that several of these cells produce the vitamin $D$ hormone suggested that vitamin $D$ could have immunoregulatory properties, and now potent immunomudulatory activities on dendritic cells, Th1 and Th17 cells, as well as $B$ cells have been confirmed. Patients with undifferentiated connective tissue disease also show vitamin D deficiency and, interestingly, patients who progress into connective tissue diseases have lower vitamin $D$ levels than those who remain in the undifferentiated connective tissue disease stage.
\end{abstract}

Vitamin D deficiency and autoimmune diseases The recent study by Zold and colleagues [1] reports that a seasonal variance in levels of $25(\mathrm{OH}) \mathrm{D} 3$ was identified in patients with undifferentiated connective tissue disease (UCTD) and showed that these levels were, in any case, significantly lower than in controls during the corresponding seasons. The results showed also that more severe vitamin $D$ deficiency in UCTD patients may play a role in the subsequent progress into well-defined connective tissue diseases (CTDs).

Epidemiological evidence indicates a significant association between vitamin $D$ deficiency and an increased incidence of autoimmune diseases [2]. Serum levels of vitamin D have been found to be significantly lower in patients with systemic lupus erythematosus (SLE) and type-1 diabetes mellitus than in the healthy population [3]. In addition, it was also found that lower levels of vitamin D were associated with higher disease activity in rheumatoid arthritis [4]. An inverse correlation has been described between the supplementation of vitamin $D$ and the development of type-1 diabetes mellitus and multiple sclerosis [5].
Low serum levels of vitamin D3 might be partially related, among other factors, to prolonged daily darkness (reduced activation of pre-vitamin $D$ by ultraviolet $B$ sunlight), different genetic backgrounds (that is, vitamin D receptor polymorphism) and nutritional factors, and could explain the latitude-related prevalence of autoimmune diseases such as rheumatoid arthritis (RA) when considering the potential immunosuppressive roles of vitamin D [2].

\section{Vitamin D or hormone D?}

The term vitamin D is, unfortunately, an imprecise term, referring to one or more members of a group of steroid molecules (seco-steroids). The A, B, C, and D ring structure is derived from the cyclopentanoperhydrophenanthrene ring structure of steroids. In particular, seco-steroids are those in which one of the rings has been broken [2].

Vitamin D, also known as cholecalciferol, is mainly generated in the skin of animals when one of the rings of the precursor molecule 7-dehydrocholesterol has been broken by ultraviolet $B$ light (UV-B, sun light). Vitamin D (or hormone D) is thus not a true vitamin, because individuals with adequate exposure to sunlight do not require dietary supplementation. Although vitamin $D$ is consumed in food, dietary intake alone is often insufficient, supplying only $20 \%$ of the body's requirements [2]. Finally, the liver and kidney help convert vitamin D to its active hormone forms (vitamin D3 hormone).

There is increasing evidence that steroid hormones (vitamins D2 and D3) derived from vitamin D act through classic nuclear receptors (nuclear vitamin D receptors (VDRs)), as well as specific binding sites on the plasma membrane of target cells that are coupled to signal transduction systems. Clarification of the physiological role of endogenous VDR

1,25(OH)2D3 = 1 $\alpha, 25(\mathrm{OH}) 2$-vitamin D3; CTD = connective tissue disease; RA = rheumatoid arthritis; SLE = systemic lupus erythematosus; $\mathrm{UCTD}=$ undifferentiated connective tissue disease; $\mathrm{VDR}=$ vitamin $\mathrm{D}$ receptor. 
agonists in the regulation of autoimmune responses will support the pharmacological VDR agonists for use in the clinic [6]. The antiproliferative, prodifferentiative, immunomodulatory and anti-inflammatory properties of synthetic VDR agonists could be exploited to treat a variety of autoimmune rheumatic diseases.

Vitamin D3 produces biological responses as a consequence of its metabolism into $1 \alpha, 25(\mathrm{OH}) 2$-vitamin $\mathrm{D} 3(1,25(\mathrm{OH}) 2 \mathrm{D} 3)$ and 24R,25(OH)2-vitamin D3. The metabolic production of these two seco-steroids and their generation of a plethora of biological actions that are attributable to the parent vitamin D3 are orchestrated via the integrated operation of the hormone $D$ endocrine system [6]. This system is very similar in its organization to that of classic endocrine systems and is characterized by an endocrine gland (the kidney, the source of the two steroid hormones), target cells that possess receptors for the steroid hormones, and a feed-back loop involving changes in serum calcium that alter the secretion of parathyroid hormone (a stimulator of the renal 1-hydroxylase), which modulates the output of the D steroid by the kidney [7].

\section{Vitamin D hormone and the immune response}

In recent years, the discovery of the VDR in the cells of the immune system and the fact that several of these cells produce vitamin $D$ hormone suggested that vitamin $D$ could have immunoregulatory properties. VDR agonists seem primarily to inhibit dendritic cell differentiation, and pathogenic pro-inflammatory T cells, such as Th1 and Th17 cells, and, under appropriate conditions, they seem to promote a deviation to the Th2 pathway [2]. In addition, two types of cells are induced by $1,25(\mathrm{OH}) 2 \mathrm{D} 3$, the $\mathrm{T}$ regulatory cells (Tregs) and the natural killer T cells; induction of these regulatory cells and direct inhibition of Th1 cells are the mechanisms by which $1,25(\mathrm{OH}) 2 \mathrm{D} 3$ suppresses experimental autoimmunity [8].

Clearly, topical hormone D analogs are efficient in modulating skin immune response in psoriasis [9]. In addition, vitamin D may play an important role in the maintenance of $B$ cell homeostasis and the correction of vitamin $D$ deficiency may be useful in the treatment of B cell-mediated autoimmune rheumatic disorders such as SLE [10]. The hormone D immunomodulatory and anti-inflammatory activities might be particularly efficient in RA patients and support a therapeutic role of $1,25(\mathrm{OH}) 2 \mathrm{D} 3$ in such disease.

\section{Conclusion}

The new study by Zold and colleagues reporting that, during the average 2.3 year follow-up period, $21.7 \%$ of patients with UCTD and a deficiency of vitamin D metabolites (hormone D) further developed well established autoimmune CTD is of great interest [1]. Patients who progressed into CTDs had lower vitamin $D$ levels than those who remained in the UCTD stage and UCTD most frequently progressed into RA, SLE, Sjögren's syndrome and mixed connective tissue disease [1]. Therefore, vitamin D hormone deficiency is also confirmed in
UCTD and might represent a new possible risk factor for the progression into well defined autoimmune rheumatic diseases.

\section{Competing interests}

The author declares that they have no competing interests.

\section{References}

1. Zold E, Szodoray P, Gaal J, Kappelmayer J, Csathy L, Gyimesi E Zeher M, Szegedi G, Bodolay E: Vitamin D deficiency in undifferentiated connective tissue disease. Arthritis Res Ther 2008, 10:R123

2. Cutolo M: Vitamin $D$ and autoimmune rheumatic diseases. Rheumatology 2008 [Epub ahead of print].

3. Cutolo $M$, Otsa K: Review: vitamin $D$, immunity and lupus. Lupus 2008, 17:6-10.

4. Cutolo M, Otsa K, Laas K, Yprus M, Lehtme R, Secchi ME, Sulli A, Paolino S, Seriolo B: Circannual vitamin D serum levels and disease activity in rheumatoid arthritis: Northern versus Southern Europe. Clin Exp Rheumatol 2006, 24:702-704.

5. Littorin B, Blom P, Scholin A, Arnqvist HJ, Blohme G, Bolinder J, Ekbom-Schnell A, Eriksson JW, Gudbjornsdottir S, Nystrom L, Ostman J, Sundkvist G: Lower levels of plasma 25-hydroxyvitamin $D$ among young adults at diagnosis of autoimmune type 1 diabetes compared with control subjects: results from the nationwide Diabetes Incidence Study in Sweden (DISS). Diabetologia 2006, 49:2847-2852.

6. Adorini A, Penna G: Control of autoimmune diseases by the vitamin D endocrine system. Nat Clin Pract Rheumatol 2008, 4: 404-412.

7. Norman AW, Henry HL, Bishop JE, Song XD, Bula, Okamura WH: Different shapes of the steroid hormone $1 \alpha, 25(\mathrm{OH}) 2$-vitamin D3 act as agonists for two different receptors in the vitamin D endocrine system to mediate genomic and rapid responses. Steroids 2001, 66:147-158.

8. Adams JS, Hewison M: Unexpected actions of vitamin D: new perspectives on the regulation of innate and adaptive immunity. Nat Clin Pract Endocrinol Metab 2008, 4:80-90.

9. Sigmundsdottir $\mathrm{H}$ an J, Debes GF, Alt C, Habtezion A, Soler D, Butcher EC: DCs metabolize sunlight-induced vitamin D3 to 'program' T cell attraction to the epidermal chemokine CCL27. Nat Immunol 2007, 8:285-293.

10. Chen S, Sims GP, Chen XX, Gu YY, Chen S, Lipsky PE: Modulatory effects of 1,25-dihydroxyvitamin D3 on human B cell differentiation. J Immunol 2007, 179:1634-1647. 